\title{
Epidural anaesthesia for ureteral reimplantation in an infant with congenital tracheal stenosis
}

\author{
Mario Concha MD, \\ Julio González MD, \\ Alejandro González MD, \\ Jorge Dagnino MD, \\ Rodolfo Molina MD
}

Purpose: We report a case of an infant with severe congenital tracheal stenosis who underwent ureteral reimplantation using lumbar epidural anaesthesia combined with light general anaesthesia.

Clinical features: A six-month-old girt with symptomatic tracheal stenosis, demonstrated by computed tomography, was scheduled for ureteral reimplantation. She received continuous lumbar epidural anaesthesia with bupivacaine $0.25 \%$ through a 21 gauge catheter positioned at $\mathrm{L}_{3-4}$ interspace. Nitrous oxide/oxygen $50 \%$ and sevoflurane 1.5-2\% were administered through a face mask and spontaneous breathing was preserved. Anaesthesia and surgery were uneventful. Postoperative epidural analgesia with bupivacaine $0.2 \%$ was excellent. The epidural catheter was withdrawn $48 \mathrm{hr}$ postoperatively and she was discharged from the hospital five days later.

Conclusion: Airway management is a major anaesthetic consideration in an infant with tracheal stenoses requiring abdominal surgery. We have demonstrated that regional anaesthesia combined with light general anaesthesia via face mask is an acceptable option, providing good analgesia during and after surgery. The technique preserves spontaneous ventilation and avoids tracheal manipulation.

Objectif : Décrire la prise en charge d'une enfant porteuse d'une sténose trachéale congénitale grave opérée pour une réimplantation urétérale sous anesthésie épidurale lombaire combinée à une anesthésie générale légère.

Éléments cliniques : Une petite fille de six mois porteuse d'une sténose trachéale symptomatique prouvée par tomographie axiale était programmée pour une réimplantation urétérale. Une anesthésie épidurale continue lombaire a été réalisée avec de la bupivacaine $0,25 \%$ et un cathéter $2 / G$ inséré à au niveau de $L_{2.3}$. Du sévoflurane 1.5-2\% dans du protoxyde d'azote/oxygène à $50 \%$ a été administré au masque en ventilation spontanée. L'anesthésie et la chirurgie se sont déroulées sans incidents. L'analgésie épidurale avec de la bupivacaine $0,2 \%$ a été d'excellente qualité. Le cathéter épidural a été retiré $48 \mathrm{~h}$ après l'intervention et l'enfant a reçu son congé de l'hópital cinq jours plus tard.

Conclusion : Pour une intervention majeure, la prise en charge des voies aériennes de l'enfant porteur d'une sténose trachéale constitue un aspect très important de l'anesthésie. Nous avons démontré que l'anesthésie régionale combinée à une anesthésie générale légère administrée avec un masque facial constituait une option acceptable produisant une bonne analgésie pendant et après l'intervention. Cette technique favorise la ventilation spontanée et évite les manipulations trachéales.

From the Department of Anaesthesiology, Catholic University of Chile, Marcoleta 347, Santiago, Chile. Address correspondence to: Dr Mario Concha; Phone: 56-2-6398766, 56-2-6382933; Fax: 56-2-6327620. Accepted for publication, March 28, 1997. 


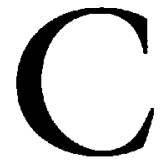

ONGENITAL tracheal stenosis (CTS) is an uncommon malformation compromising variable lengths at any level of the trachea. Management is determined by the severity of the stenosis and ranges from observation to dilation or other surgical procedures including tracheal resection or tracheoplasty using costal, cartilage or dural grafts. ${ }^{1}$

When children with CTS present for surgery not involving the trachea, their course can be complicated if the anaesthetic plan includes intubation and ventilation. Problems for the anaesthetist may arise from airway obstruction due to secretions or postoperative oedema, difficult intubation, high insufflation pressures, or associated malformations. Regional anaesthesia is an option in the management of patients undergoing infraumbilical surgery as it provides good surgical conditions while avoiding tracheal intubation. However, there are no previous reports of it use in infants with CTS.

We describe our management of a child with CTS who underwent continuous lumbar epidural anaesthesia, supplemented by mask general anaesthesia, for ureteral reimplantation.

\section{Case report}

A six-month-old, $8-\mathrm{kg}$, girl, with repeated episodes of urinary tract infection, due to vesico-ureteral reflux was scheduled for ureteral reimplantation. She had experienced stridor and chest retraction since the first month of life: symptoms were worse when she was agitated or crying and subsided when sleeping. Computed tomography one week before surgery demonstrated tracheal stenosis from $2 \mathrm{~cm}$ below the vocal cords to the tracheal bifurcation, with a tracheal diameter of $3.2 \mathrm{~mm}$. No other malformations were found. Physical examination revealed a respiratory rate of $26 \mathrm{bpm}$, inspiratory and expiratory stridor, and moderate supraclavicular retraction. Oxygen saturation breathing room air was $95 \%$. Apart from the abnormal CT scan, laboratory tests were normal.

Induction of anaesthesia was commenced with spontaneous breathing using $\mathrm{N}_{2} \mathrm{O} 50 \%$ in oxygen, and sevoflurane $3-5 \%$. After approximately five minutes, an epidural block was performed with the infant in the lateral decubitus position, using a median approach with a 19-gauge Tuohy needle at the $\mathrm{L}_{3-4}$ interspace. The extradural space was identified using loss of resistance, and a 21 gauge epidural catheter was introduced $4 \mathrm{~cm}$ into the space. Bupivacaine $0.25 \%, 1$ $\mathrm{ml} \cdot \mathrm{kg}^{-1}$, was administered, and surgery began $15 \mathrm{~min}$ later. The level of the epidural block was not determined, but as there were no increases in arterial pres- sure, heart and respiratory rates in response to surgical incision this was considered indicative of successful epidural blockade. Anaesthesia was maintained with spontaneous ventilation using $\mathrm{N}_{2} \mathrm{O} 50 \%$ in oxygen and sevoflurane 1.5-2\% through a Jackson Rees circuit and face mask. Surgical conditions were excellent. Oxygen saturation was $95-97 \%$, and heart rate and arterial pressure varied $<20 \%$ from basal values. At the end of surgery, which lasted two hours, inhaled agents were stopped and the infant emerged from anaesthesia three minutes later. She was transferred to the paediatric intensive care unit for respiratory monitoring and to the surgical ward on the next day.

Epidural analgesia with $0.5 \mathrm{ml} \cdot \mathrm{kg}^{-1}$ bupivacaine $0.2 \%$ every six to eight hours gave excellent pain relief for approximately eight hours and no other analgesic drugs were required. The epidural catheter was withdrawn $48 \mathrm{hr}$ after surgery. The remainder of her hospital course was uneventful and she was discharged from the hospital five days later.

\section{Discussion}

The two most important anaesthetic problems related to CTS in infants are the choice of anaesthesia and airway management. The most feared complication is complete airway obstruction due to secretions or oedema secondary to tracheal intubation.

Continuous epidural anaesthesia provided excellent surgical and ventilatory conditions in this infant with CTS. General anaesthesia and tracheal intubation were considered, but the problems related to difficult intubation and ventilation and the possibility of airway obstruction, made this a less attractive choice than a regional technique combined with light inhalational anaesthesia through a face mask.

Regional anaesthesia has been recommended in adult patients with tracheal stenosis ${ }^{2}$ to avoid tracheal intubation, but the situation is more complex in paediatric patients. Lack of cooperation implies that general anaesthesia is induced before the regional anaesthesia procedure. During surgery, ventilation must be assisted, at least partially. The manner in which this should be done is not clear. Tracheal intubation with the endotracheal tube positioned above or below the stenosis has been suggested, ${ }^{3,4}$ but the difficulties related to proper fixation of the tube and the risk of post intubation oedema discouraged us from using this technique. A laryngeal mask with controlled or spontaneous ventilation has been reported as an alternative for pulmonary ventilation in adult and paediatric patients with CTS. ${ }^{3,5}$ Leakage, at the high inflation pressures sometimes required in these patients, the possibility of bronchospasm at light levels of 
anaesthesia, ${ }^{3}$ and inability to ventilate ${ }^{6}$ must be considered as risks when a laryngeal mask is used.

Regional techniques have been widely and safely used in paediatric patients. ${ }^{7-9}$ Satisfactory surgical conditions, avoiding or reducing the use of opioids and muscle relaxants, preservation of haemodynamic conditions, rapid and safe emergence from anaesthesia ${ }^{10,11}$ and effective post operative analgesia, are some of the advantages of regional anaesthesia in paediatric patients. Limitations to its use are experience of the anaesthetist and the availability of proper equipment.

We chose regional anaesthesia combined with light general anaesthesia because of the potential for serious airway compromise if the trachea was intubated. Epidural was preferred to spinal anaesthesia because it gave the possibility of titrating the local anaesthetic during and after the operation. The excellent surgical conditions allowed us to use low sevoflurane concentrations, and to avoid the use of opioids and muscle relaxants, preserving spontaneous ventilation and permitting a fast and safe emergence from anaesthesia. Continuous caudal anaesthesia could have been an alternative. However, the risk of septic complications in relation to the permanence of the epidural catheter inclined us to choose the lumbar approach to the epidural space.

Failure of the regional technique or an intraoperative complication could make the control of the airway mandatory. In this case, we believe that tracheal intubation and fixation of the tube above the stenosis is the safest choice rather than trying to force the tube through the stenotic segment. If premature failure of the regional anaesthesia were detected, probably the safest alternative would have been to postpone surgery with a satisfactory regional anaesthesia in place.

In summary, we report the case of an infant with a severe CTS, in whom epidural anaesthesia combined with light general anaesthesia via face mask, gave excellent surgical conditions, preserved spontaneous ventilation and avoided manipulation of the trachea.

\section{References}

1 Lobe TE, Hayden KC, Nicolas D, Richardson J. Successful management of congenital tracheal stenosis in infancy. J Pediatr Surg 1987; 22: 1137-42.

2 Sutcliffe N, Remington SAM, Ramsay TM, Mason C. Severe tracheal stenosis and operative delivery. Anaesthesia 1995; 50: 26-9.

3 Asai $T$, Fujise $K$, Uchida $M$. Use of the laryngeal mask in a child with tracheal stenosis. Anesthesiology 1991; 75: $903-4$.

4 Takasaki $\Upsilon$, Hayashi $\Upsilon$, Takaki $O$, Uchida $O$, Kuro $M$. Unexpected congenital tracheal stenosis in infants with congenital heart disease (Letter). Anesth Analg 1993; 77: 198-9.

5 Asai $T$, Fujise $K$, Uchida $M$. Laryngeal mask and tracheal stenosis (Letter). Anaesthesia 1993; 48: 81.

6 Kokkinis K, Papageorgiou E. Failure of the laryngeal mask airway (LMA) to ventilate patients with severe tracheal stenosis. Resuscitation 1995; 30: 21-2.

7 Yaster M, Maxwell LG. Pediatric regional anesthesia. Anesthesiology 1989; 70: 324-38.

8 Dalens $B$. Regional anesthesia in children. Anesth Analg 1989; 68: 654-72.

9 Flandin-Bléty $C$, Barrier $G$. Accidents following extradural analgesia in children. The results of a retrospective study. Paediatr Anaesth 1995; 5: 41-6.

10 Delleur $M$, Murat I, Esteve E, Raynaud P, Gaudiche $O$, Saint-Maurice $C$. Continuous epidural anaesthesia less than two years old. (French) Ann Fr Anesth Réanim 1985; 4: 413-7.

11 Murat I, Delleur MM, Esteve C, Egu JF, Raynaud P, Saint-Maurice $C$. Continuous extradural anaesthesia in children. Clinical and haemodynamic implications. $\mathrm{Br} \mathrm{J}$ Anaesth 1987; 69: 1441-50. 